\title{
Microstructural Investigation of the Effects of Carbon Black Nanoparticles on Hydration Mechanisms, Mechanical and Piezoresistive Properties of Cement Mortars
}

\author{
Gustavo Emilio Soares de Lima ${ }^{a}\left(\left[\right.\right.$, , Gustavo Henrique Nalon ${ }^{a *}$ (1), Rodrigo Felipe Santos ${ }^{a}$ (1), \\ José Carlos Lopes Ribeiro ${ }^{\circledR}$ (), José Maria Franco de Carvalho ${ }^{\circledR}$ (D), Leonardo Gonçalves Pedrotia ${ }^{a}$ (D),
}

Eduardo Nery Duarte de Araújo ${ }^{b}$

${ }^{a}$ Universidade Federal de Viçosa, Departamento de Engenharia Civil, Viçosa, MG, Brasil.
${ }^{b}$ Universidade Federal de Viçosa, Departamento de Física, Viçosa, MG, Brasil.

Received: November 26, 2020; Revised: April 11, 2021; Accepted: May 11, 2021

\begin{abstract}
Carbon-black nanoparticles (CBN) have been incorporated into cement-based materials for improvement of mechanical or self-sensing properties. There is no previous research focused on the microstructural evaluation of effects of $\mathrm{CBN}$ on both parameters. In this work, mortars containing different CBN contents were produced, cured for 28 days, and subjected to electron microscopy (SEM), $\mathrm{X}$-ray diffraction (XRD) and Raman spectroscopy. Tests for determination of compressive strength, modulus of elasticity and piezoresistivity response were developed. SEM indicated that lower CBN contents refined the cementitious matrix, while higher contents increased the volume of voids. XRD and Raman spectroscopy indicated hydration improvements for CBN contents between $0.375 \%$ and $3 \%$. The best mechanical improvements were provided by concentrations of CBN up to $3 \%$. CBN contents of $5 \%$ and $6 \%$ provided the best sensing properties. The optimal concentration was found to be $5 \%$ of $\mathrm{CBN}$, since it provided excellent piezoresistivity, without significant mechanical properties loss.
\end{abstract}

Keywords: Smart cement-based composites, Carbon black nanoparticles, Hydration mechanisms, Piezoresistivity, Mechanical properties.

\section{Introduction}

Functional nanomaterials have been added to mortars and concretes for production of smart composites able to work as structural elements and systems that monitor strain and damage in smart civil structures ${ }^{1-3}$. As these multifunctional cement-based materials have structural and sensing abilities, their use reduces or eliminates the need for conventional Structural Health Monitoring (SHM) architectures, which simplifies the design and allows structures to be more compact ${ }^{2,4}$.

Recently, many studies have focused on the improvement of mechanical or self-sensing properties of cementitious materials through the incorporation of different kinds of conductive fillers. Among them, carbon black nanoparticles (CBN) have received increasing attention. $\mathrm{CBN}$ present high specific surface area, low electrical resistivity, small average particle size and lower production cost, which can provide improvements of mechanical properties, durability, electrical conductivity and sensing ability to cement-based materials ${ }^{5-7}$.

Various effects of $\mathrm{CBN}$ on the mechanical properties of pastes, mortars and concretes were reported in the literature. Dai et al. ${ }^{8}$ and Dong et al. ${ }^{9}$ observed decreases in mechanical properties of pastes produced with $\mathrm{CBN}$ concentration ranging from $0.1 \%$ to $6 \%$, by weight of cement. These reductions were mainly attributed to the adsorption of CBN on the surface of cement, which hinders the hydration process ${ }^{8}$. In

*e-mail: gustavo.nalon@ufv.br addition, there is poor cohesion between the cement matrix and the nanofillers, which tend to adsorb a fraction of water leading to decreases in mechanical strength ${ }^{9}$. On the other hand, Rezania et al..$^{10}$ reported reductions of mechanical properties of concretes for $\mathrm{CBN}$ contents between $0.4 \%$ and $1.2 \%$, followed by improvements in these parameters for CBN contents higher than $1.2 \%$. Monteiro et al. ${ }^{7}$ verified improvements of compressive strength and tensile strength of mortars with addition of CBN contents of $1 \%, 4 \%$ and $7 \%$. When the concentration of CBN was higher than $10 \%$, they observed segregation and extremely low strength values. Dehghanpour et al. ${ }^{11}$ also verified a progressive improvement of mechanical properties of concretes with $3 \%, 6 \%$ and $10 \%$ of CBN. Strength improvements have been attributed to a physical phenomenon based on filler effects and strengthening of the interface bondage between hydrates and CBN due to the high chemical activity of the nano-size functional fillers ${ }^{8}$.

The high electrical conductivity of CBN can decrease the electrical resistivity of cement-based materials to values close to the electrical resistivity of semiconductors ${ }^{6,7,12}$. When the conductive filler concentration is close to the percolation threshold, the tunneling conduction mechanism is dominant, which provides an excellent piezoresistive response to the cementitious composites ${ }^{13,14}$. Consequently, they can be used as sensors for monitoring strain in concrete structures. The electrical resistivity of CBN-based composites changes significantly when they are subjected to deformation due to 
variations of the distance between neighboring $\mathrm{CBN}$ and changes of conductive pathways ${ }^{5,15}$. The electrical conductivity and the piezoresistivity of cement-based composites containing CBN has been investigated in different studies ${ }^{5-7,9,15-22}$.

Previous studies reported optimal contents of CBN for improvement of mechanical strength different from those that guarantee an improvement of the piezoresistive response of smart cement-based materials. There is no previous research focused on the microstructural evaluation of the effects of $\mathrm{CBN}$ on both parameters, in order to detect an optimal content that provides low electrical resistivity and good piezoresistive response, without significant loss of mechanical properties. In addition, according to the authors' knowledge, none of the previous studies about the incorporation of $\mathrm{CBN}$ in cement-based materials evaluated their microstructure with X-ray diffraction and Raman spectroscopic techniques. Therefore, the present study developed a microstructural evaluation of the influence of CBN on both mechanical and piezoresistive properties of mortars and provided different new contributions: (i) the cement hydration mechanisms in CBN-based cementitious composites were analyzed based on a combination of techniques of scanning electron microscopy (SEM), X-ray diffraction (XRD) and Raman spectroscopy; (ii) significant improvements in mechanical strength, static elastic modulus and self-sensing ability of CBN-based mortars were achieved, in comparison to results of previous studies; (iii) an optimal balance between mechanical and piezoresistivity properties of CBN-based cementitious composites was proposed.

\section{Experimental}

The conductive nanofillers used in this study were Raven P5 Ultra carbon blacks with specific surface area of $100 \mathrm{~m}^{2} / \mathrm{g}$, dibutyl phthalate (DBP) absorption number of $117 \mathrm{~cm}^{3} / 100 \mathrm{~g}$, particle size of $20 \mathrm{~nm}$ and supplied by Birla Carbon. The surface area and the particle size were obtained from the manufacturer product datasheet. They were determined according to the ASTM D $6556^{23}$ and ASTM D3849 ${ }^{24}$, respectively. Cement-based composites were produced with CP II E-32 Portland cement with density of $2.95 \mathrm{~g} / \mathrm{cm}^{3}$ and equivalent to the type I (SM) cement of ASTM C59525, quartzite sand with maximum diameter of particles of $1.2 \mathrm{~mm}$ and bulk specific gravity of 2.65 , and polycarboxylate superplasticizer (SP) with density of $1.12 \mathrm{~g} / \mathrm{cm}^{3}$ provided by MC Bauchemie to be used as received.

In order to develop a microstructural analysis of the influence of $\mathrm{CBN}$ on the mechanical and piezoresistive properties of mortars, series with eight different $\mathrm{CBN}$ concentrations were considered: $0 \%, 0.375 \%, 0.75 \%, 1.5 \%, 3 \%, 4 \%, 5 \%$ and $6 \%$ (by weight of cement). The mix proportions (in mass) of each composition are indicated in Table 1. To obtain mortar mixtures with suitable workability and ensure good compaction, previous research ${ }^{5,26}$ recommended to increase the SP dosage with the increase in $\mathrm{CBN}$ content. Therefore, in order to always achieve a minimum flow index of $220 \mathrm{~mm}$ (diameter of spread of the fresh mixture in a flow table test, according to prescriptions of ABNT NBR $13276^{27}$ ), the mortars of the present study were produced with concentrations between $0 \%$ and $2.75 \%$ (by weight of cement) of a polycarboxylate SP solution (MC-Powerflow 4001) provided by the manufacturer for use as received. Eight mortar prisms measuring $4 \mathrm{~cm} \times 4$ $\mathrm{cm} \times 7.5 \mathrm{~cm}$ were produced for each series, according to the procedures described above. During the fabrication process, a small amount of paste was poured in sealed plastic vials and stored in the moisture room at $(23 \pm 2)^{\circ} \mathrm{C}$ and relative humidity of $95 \%$, as recommended by Garg et al. ${ }^{28}$. Two $1.5 \mathrm{~cm} \times 5.0 \mathrm{~cm} \times 0.1 \mathrm{~cm}$ copper plates were embedded in four prisms in a straight line, at equal distance of $2.0 \mathrm{~cm}$ from each other, while no electrodes was embedded in the others.

After a 28-days curing time, samples were oven dried for 24 hours at $(100 \pm 5)^{\circ} \mathrm{C}$ and cooled down to room temperature before the piezoresistive tests, following recommendations of Mohsen et al. ${ }^{29}$ and Kim et al..$^{30}$. After the same curing period, the samples in the sealed plastic vials were uncovered and subjected to the SEM, XRD and Raman analyses described in the next sections. In each series, one of the prisms with copper electrodes (designated as S4) was used to estimate the ultimate strength of the composite. The other composites with embedded electrodes (designated as S1, S2 and S3) were subjected to the biphasic DC measurement and to the piezoresistive test described in the following sections. Next, one of the specimens without electrodes was also used to estimate the mortar compressive strength $\left(f_{u}\right)$. The others were used to determine the static modulus of elasticity and the compressive strength of the material, according to the procedures described above.

\subsection{Specimens casting and curing}

Firstly, dry materials were prepared according to the designed proportions. Superplasticizer and CBN were mixed with water in a stirring pot for one minute and then subjected to an ultrasonication process for 10 minutes, using a probe sonicator with frequency of $20 \mathrm{kHz}$ and $50 \mathrm{~W}$ of power. After that, cement was placed into the stirring pot and stirred for seven minutes. Finally, the required amount

Table 1. Mix proportions (in mass)

\begin{tabular}{lccccc}
\hline \multicolumn{1}{c}{ Series } & Cement & Sand & Water & CBN & SP \\
\hline REF & 1.00 & 0.90 & 0.45 & 0.00000 & 0.0000 \\
\hline CBN0.375\% & 1.00 & 0.90 & 0.45 & 0.00375 & 0.0005 \\
\hline CBN0.75\% & 1.00 & 0.90 & 0.45 & 0.00750 & 0.0009 \\
\hline CBN1.5\% & 1.00 & 0.90 & 0.45 & 0.01500 & 0.0024 \\
\hline CBN3\% & 1.00 & 0.90 & 0.45 & 0.03000 & 0.0076 \\
\hline CBN4\% & 1.00 & 0.90 & 0.45 & 0.04000 & 0.0128 \\
\hline CBN5\% & 1.00 & 0.90 & 0.45 & 0.05000 & 0.0194 \\
\hline CBN6\% & 1.00 & 0.90 & 0.45 & 0.06000 & 0.0275 \\
\hline
\end{tabular}


of sand was added and mixed for four minutes. The stirred mixture was then poured into oiled molds. They were put on a vibrating table and shaken for 10 seconds. After demolded, all the specimens were cured in a moisture room with a constant temperature of $(23 \pm 2){ }^{\circ} \mathrm{C}$ and relative humidity of $95 \%$ for 28 days.

\subsection{Scanning electron microscopy (SEM)}

Scanning electron microscopy (SEM) was performed using a JEOL's JSM-6010LA microscope operating at $20 \mathrm{kV}$, in order to obtain secondary electron images of the samples.

\subsection{X-ray diffraction (XRD)}

XRD tests were performed in a D8Discover diffractometer with $\mathrm{CuK} \alpha$ radiation $(\lambda=1.5418 \AA)$, working voltage of $40 \mathrm{kV}$ and electric current of $40 \mathrm{~mA}$. Samples were scanned from $20^{\circ}$ to $65^{\circ}(2 \theta)$, with a $0.05^{\circ}$ step size and an accumulated time per step of $1 \mathrm{~s}$.

\subsection{Raman spectroscopy}

Raman spectra were collected with a Renishaw inVia spectrometer with a HeNe laser of $633 \mathrm{~nm}(1 \mathrm{~mW})$ as excitation source. Previous research ${ }^{28,31,32}$ stated that one of the main advantages of Raman analysis is the fact that special sample preparation is not required: although Raman spectroscopy is a surface sensitive technique, it develops a characterization just a few microns in depth. The application of polishing/etching techniques is not needed, so that they could be destructive to the sample surface and hence not completely representative.

In the present work, a randomly chosen area of $200 \mu \mathrm{m}$ x $200 \mu \mathrm{m}$ of the sample without polishing was successfully brought into focus with $20 \times$ objective lens. Then, a Raman map of the area was elaborated. In order to obtain more representative results, the mapping area used in the present work was larger than those of Raman maps of concretes presented by Machoviè et al. ${ }^{33}(30 \mu \mathrm{m} \times 75 \mu \mathrm{m})$, mortars presented by Schmid and Dariz ${ }^{34,35}$ (e.g., $72 \mu \mathrm{m}$ x $90 \mu \mathrm{m}, 75 \mu \mathrm{m}$ x $44 \mu \mathrm{m}$ ), and cement pastes presented by Liu and $\operatorname{Sun}^{36}(100 \mu \mathrm{m} x$ $100 \mu \mathrm{m})$ and Takahashi ${ }^{37}(170 \mu \mathrm{m} \times 170 \mu \mathrm{m})$. In order to ensure random sampling, Raman maps were constructed based on spectra collected at various locations distributed in a square grid with 81 predefined and equally spaced coordinates. In this experimental program, the wavenumber range of $110-1330 \mathrm{~cm}^{-1}$ was chosen in Raman analysis for evaluation of portlandite peaks located at $354-359 \mathrm{~cm}^{-138-42}$. Moreover, an exposure time of three seconds and one accumulation per spectrum were used. Using the software Wire 3.4 Renishaw, the collected data was subjected to a post-processing treatment for baseline correction ${ }^{28}$.

\subsection{Biphasic DC measurement technique}

Direct current (DC) methods for determination of electrical resistivity tend to induce an inherent time-based drift in cement-based materials' electrical outputs, which is associated with polarization effects ${ }^{13,43,44}$. These effects can be lessened to an acceptable range by employing alternating current (AC) signals with equal magnitudes of positive and negative peaks ${ }^{13}$. More recently, Downey et al. ${ }^{44}$ proposed a promising biphasic DC measurement approach for elimination of the polarization effect. This method was used in the present research for determination of electrical resistivity and evaluation of the piezoresistive response of the composites.

A $6 \mathrm{~Hz}$ alternating square wave voltage signal ranging from $-5 \mathrm{~V}$ to $+5 \mathrm{~V}$ with a duty cycle of $50 \%$ was generated by an Arduino Mega 2560 R3 microcontroller board. A reference resistor with electrical resistance $R_{\text {ref }}=1000 \Omega$ was placed in series with each cement-based composite. Voltage drops across the reference resistor and the composite $\left(U_{\text {ref }}\right.$ and $U_{\text {comp }}$, respectively) were measured with a LabVIEW script interfaced over a NI DAQ-9178 chassis with a NI9219 universal analog input module. Then, it was possible to calculate the electric current $i$ in the circuit and the electrical resistance of the composite. Finally, the electrical resistivity of the system could be estimated, based on the distance between electrodes $L$ and the effective area $A$ of the voltage pole.

\subsection{Piezoresistivity analysis}

Electromechanical tests of the composites were performed to investigate their piezoresistive behavior. The specimens were subjected to a cyclical load test followed by a step test. The compression load was applied at $600 \mathrm{~N} / \mathrm{s}$. In the cyclical load test, maximum compressive loads lower than $30 \%$ of the material's estimated ultimate load $\left(f_{u}\right)$ were applied. The step test consisted of 5-seconds load steps at $10 \%, 20 \%$ and $30 \%$ of the material's estimated ultimate load. A clip-gauge was used to measure the longitudinal strain at two opposite faces of the sample. The experimental setup is presented in Figure 1. The electrical resistance of the material was measured through the biphasic DC measurement approach mentioned in the previous section, in order to determine the fractional change in electrical resistivity (FCR) and the gauge factor (GF) of the material, as defined in Equation 1.

$G F=\frac{F C R}{\varepsilon}=\frac{\frac{\Delta R}{R_{0}}}{\varepsilon} \approx \frac{\frac{\Delta \rho}{\rho_{0}}}{\varepsilon}$

where $R_{0}$ and $\rho_{0}$ are the initial electrical resistance and resistivity, respectively, $\varepsilon$ is the compressive strain, and $\Delta \mathrm{R}$ and $\Delta \rho$ are the variation of electrical resistance and resistivity, respectively.

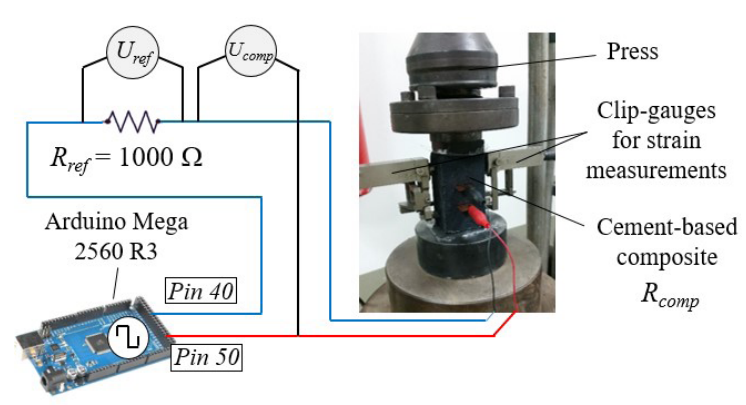

Figure 1. Experimental setup for evaluation of piezoresistive response of the composites. 


\subsection{Mechanical tests}

The static modulus of elasticity and compressive strength of the specimens were determined according to the prescriptions of ABNT NBR $8522^{45}$. Compression tests were performed in an EMIC 23-600 universal testing machine. Clip-gauges were used to measure the longitudinal strain of the specimens. An automated test method was used to apply compressive loads according to the methodology A of the ABNT NBR $8522^{45}$. A loading rate of $0.50 \mathrm{MPa} / \mathrm{s}$ was used. Considering the stress-strain curve of the test, the static modulus of elasticity $E$ (in GPa) was calculated as the slope of the straight line that links the points of compressive stress (in $\mathrm{MPa})$ of $\sigma_{a}(0.5 \mathrm{MPa})$ and $\sigma_{b}\left(30 \%\right.$ of $\left.f_{u}\right)$.

\section{RESULTS AND DISCUSSION}

The effects of $\mathrm{CBN}$ concentration on the compressive strength of mortars are evidenced in Figure 2. CBN concentrations smaller than $3 \%$ provided increases in the compressive strength of the material, while higher CBN contents provided lower strength values. For example, a strength decrease of about $86 \%$ was verified when the $\mathrm{CBN}$ concentration increased from $3 \%$ to $6 \%$. A quadratic regression analysis was carried out to determine the model that provides the best fit to the experimental data. A coefficient of determination of 0.99 was obtained, which indicates that a good relationship between CBN content and mortar compressive strength could be established. This regression equation indicates a possible optimal CBN concentration between $1.5 \%$ and $3.0 \%$ to maximize the compressive strength. The hypothetical optimal point seems to be a $2.1 \%$ content, which would provide a compressive strength around $44 \mathrm{MPa}$.

Monteiro et al..$^{7}$ also verified that the compressive strength of mortars first increased and then decreased with the increase in the $\mathrm{CBN}$ content. However, they found an optimal content close to $4 \%$ and mentioned that contents higher than $10 \%$ revealed the presence of segregation and extremely low strength values. A sharp decrease in compressive strength for CBN contents of $6 \%$ was also reported by Dai et al. ${ }^{8}$ for cement pastes.

CBN affect the mechanical properties of the cementitious matrix in different ways. One of them is by filler effect, in which they fill the pores and capillaries of the matrix and provide gains in compressive and flexural strength ${ }^{10,46}$. CBN also improve the cement hydration process, as observed by Dong et al. ${ }^{18}$. Although pastes with CBN present a delay in the hydration peak in the early ages, greater cumulative

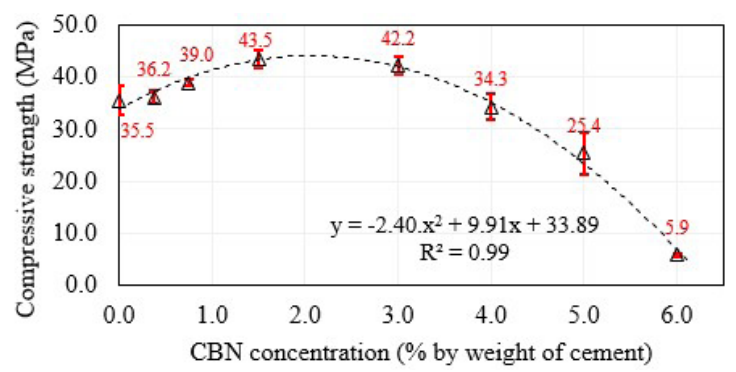

Figure 2. 28-days compressive strength of mortars with different CBN contents. heat of hydration is observed over time, as the content of $\mathrm{CBN}$ in the mixture increases. $\mathrm{CBN}$ also have high chemical activity and ensure strong bonds with cement hydrates ${ }^{8}$. On the other hand, higher concentrations of $\mathrm{CBN}$ tend to decrease the mechanical properties, probably due to the excess of nanoparticles that hinder the cementitious matrix's adhesion ${ }^{7}$. In addition, a greater amount of $\mathrm{CBN}$ can hinder the contact between cement particles and water, impairing the hydration process ${ }^{8}$. The large amount of nanofillers adsorb significant amounts of water and make it more difficult for the remaining water molecules to reach the cement particles, which impairs the development of hydration products ${ }^{9,20,47,48}$. Further research is recommended to quantify the amount of water adsorbed by CBN dispersed in the cementitious matrix, considering the effects of different curing periods and curing conditions.

A similar behavior was verified when the mortars' elasticity modulus was plotted against the $\mathrm{CBN}$ concentration (Figure 3). Improvements in modulus of elasticity were obtained for CBN contents up to $1.5 \%$. Samples with the highest filler concentration presented a modulus of elasticity $72.0 \%$ lower than the control samples. Another regression analysis was carried out and a good quadratic relationship between CBN content and modulus of elasticity could be established (the coefficient of determination was 0.83 ). The obtained quadratic equation suggests that the optimal CBN concentration seems to be close to $2.14 \%$, which would provide a modulus of elasticity close to $18.8 \mathrm{GPa}$.

A relationship between CBN content and modulus of elasticity of mortars was only previously reported by Monteiro et al. ${ }^{7}$, at the age of 120 days. They observed an increase of modulus of elasticity only for CBN contents lower than $4 \%$. For higher concentrations, the modulus of elasticity was lower than that of control samples. Improvements of 28-days compressive strength and 120-days modulus of elasticity obtained by Monteiro et al. ${ }^{7}$ were $21.3 \%$ and $41.3 \%$, respectively.

Since the relationship between compressive strength and modulus of elasticity of cement-based materials with CBN has never been established in previous works, a nonlinear regression analysis was performed to find the model that provides the best fit to the experimentally obtained mechanical properties. A functional form commonly used by structural design codes to correlate concrete mechanical properties was used and a good coefficient of determination (0.949) was obtained, as shown in Figure 4. The modulus of elasticity of cementitious materials is determined by the porosity of

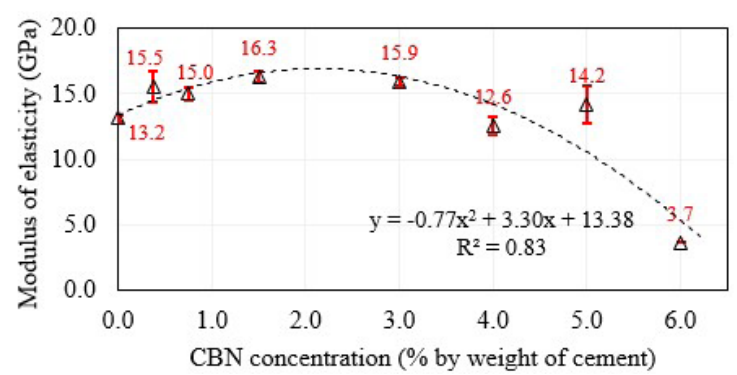

Figure 3. 28-days modulus of elasticity of mortars with different CBN contents. 


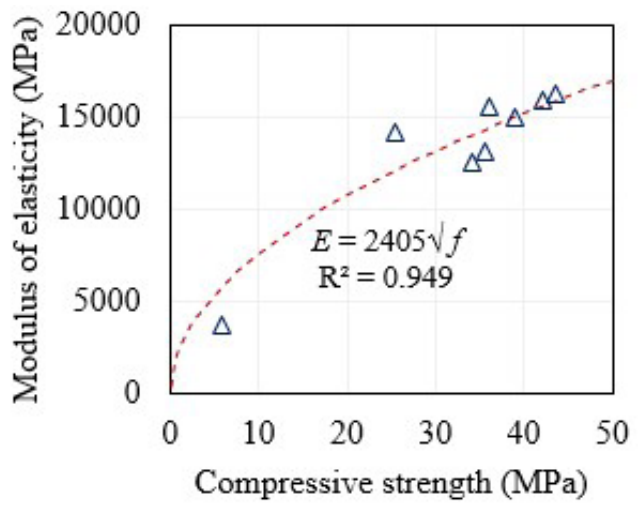

Figure 4. Relationship between 28-days compressive strength and modulus of elasticity of mortars with $\mathrm{CBN}$.

the cement paste matrix, i.e., less porous matrices tend to present higher stiffness ${ }^{49}$. Since low dosage of CBN tend to provide a filler effect and improve hydration reactions, the greater refinement of the matrix can lead to a greater modulus of elasticity. As lower porosity is also linked to higher compressive strengths, it is observed that composites with higher strengths also have greater modulus of elasticity. Therefore, the high coefficient of determination found in this work between compressive strength and modulus of elasticity is plausible and quite pertinent.

In the present study, XRD and Raman spectroscopy techniques were used to get important insights into the hydration mechanisms taking place. Raman spectroscopy is a powerful technique based on light-matter interaction that can successfully complement more consolidated techniques such as XRD analysis. It is a completely non-destructive technique that does not require sample preparation, and allows mapping the distribution of cement hydrates produced over different curing periods $\mathrm{s}^{28,34,50}$. It should be noted that these techniques were not used in previous studies dealing with investigations of the hydration process of cementitious matrices containing $\mathrm{CBN}$.

Raman maps for portlandite peaks located at $356.63 \mathrm{~cm}^{-1}$ and XRD spectra of the eight samples are presented in Figure 5 and Figure 6, respectively. The brighter spots of the Raman maps indicate locations with higher $356.63 \mathrm{~cm}^{-1}$ peak intensities. Figure 7 shows a typical Raman spectrum (after baseline correction) collected from sample CBN0.375\%, in a measurement location with high portlandite concentration. When the $\mathrm{CBN}$ increased from $0 \%$ to $3 \%$, there are an increase in the intensity of peaks of portlandite at $2 \theta=18^{\circ}, 48^{\circ}$ and $51^{\circ}$ in the XRD diffractograms and an intensification of brighter areas in the portlandite Raman maps. Since portlandite is a by-product of the cement hydration, the results prove that small CBN contents improved the hydration process and increased the mortar compressive strength and stiffness, as shown in Figure 2 and Figure 3. In fact, XRD diffractograms and Raman maps also suggest lower amounts of portlandite in series with higher $\mathrm{CBN}$ concentration (CBN4\%, CBN5\% and $\mathrm{CBN6 \%}$ ).

In addition, $\mathrm{CBN} 6 \%$ samples presented a slightly higher intensity of some peaks of alite and belite $\left(2 \theta=32.2^{\circ}\right.$ and $41.3^{\circ}$ ), in comparison to the other samples, which may suggest a delay of cement hydration. The high intensity peak at $2 \theta=23^{\circ}$ observed in the XRD diffractogram of CBN6\% samples can also indicate such cement hydration delay, since it is associated with the presence of alite. However, this XRD peak is also associated with the presence of ettringite and calcite. Previous research ${ }^{49,51,52}$ reported that ettringite is formed in the early stages of cement hydration and is later replaced by monosulfate hydrates. Nevertheless, in cements containing calcite, the formation of monocarbonate leads to an indirect stabilization of ettringite at the expense of monosulfate ${ }^{53,54}$. In order to investigate the different phenomena that affect this XRD signatures, further research is recommended to properly estimate the variations of alite, belite, and ettringite contents, as well as the formation of C-S-H hydrates after different curing periods. Due to the intrinsic amorphous characteristics of the $\mathrm{C}-\mathrm{S}-\mathrm{H}$ gel and poor crystallization of monosulfate hydrates ${ }^{55,56}$, the application of nuclear magnetic resonance (NMR) is also strongly recommended for future research on this topic.

A morphological evaluation of the composites was carried out using the SEM analysis shown in Figure 8, which was supported by the results provided by the XRD and Raman spectroscopy techniques (Figure 5 and Figure 6). XRD diffractograms and Raman maps indicated that CBN concentrations lower than 3\% (by mass of cement) led to improvements in cement hydration reactions, whereas CBN dosage higher than $4 \%$ (by mass of cement) hindered the formation of hydration products. Therefore, a densification of the pore structure could be expected to happen in composites containing low $\mathrm{CBN}$ dosage. In fact, some tendency of refinement of the pore system with additional hydration products can be observed in the SEM images of samples with lower CBN contents (Figure 8b-e), while the presence of stable hydrates is less noticeable in samples with higher amounts of CBN (Figure 8f, g). However, the use of porosimetry techniques is strongly recommended to quantify the porosity reductions. The hypothesis of matrix densification for lower concentrations of carbon nanomaterials is also supported by the gains of compressive strength and modulus of elasticity presented in Figure 2 and Figure 3.

The increase in CBN content significantly affected the electrical resistivity of the composites (Figure 9). A behavior similar to that observed in the mechanical tests was obtained for electrical resistivity: it firstly increased and then decreased with $\mathrm{CBN}$ content. The resistivity of mortars with a CBN concentration of $6 \%$ is about four orders of magnitude lower than the resistivity of plain mortars.

Curiously, an increase in electrical resistivity was observed when the CBN content increased from $0 \%$ to $3 \%$. It can be attributed to the higher densification of the cementitious matrix due to the filler effect and improvement of the hydration process suggested by the results of SEM, XRD and Raman spectroscopy techniques. These smaller functional filler contents were not able to generate electronic conduction. The conductive network was only created when $\mathrm{CBN}$ contents greater than $6 \%$ were used. With such high CBN dosage, the matrix leaves the insulating zone, since contacting and tunneling electronic conductions became very significant. A strong evidence of existing tunneling conduction was the fact that the cementitious composites with high $\mathrm{CBN}$ content 
a) REF

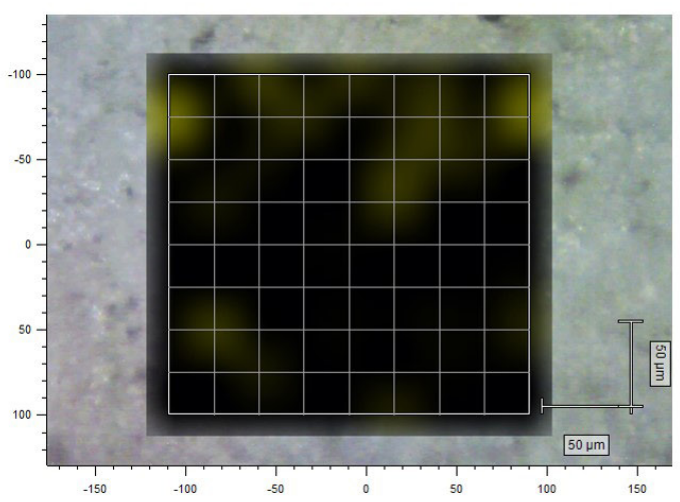

c) $\mathrm{CBN} 0.75 \%$

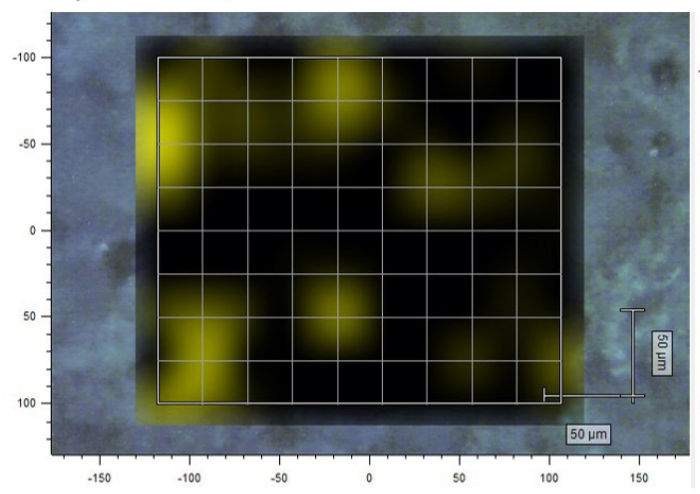

e) CBN3\%

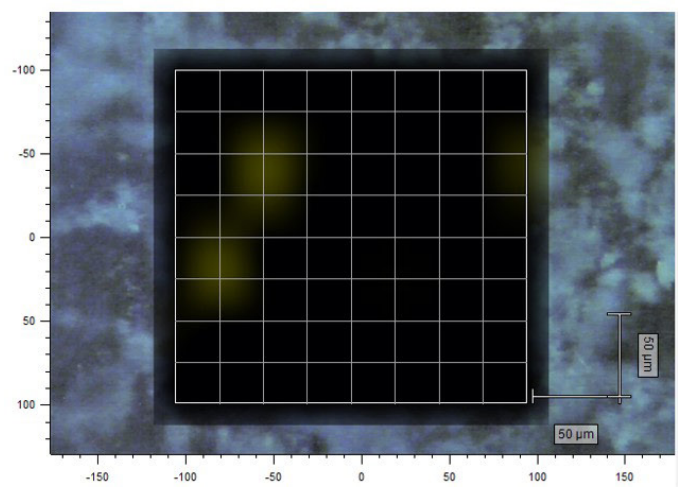

g) $\mathrm{CBN} 5 \%$

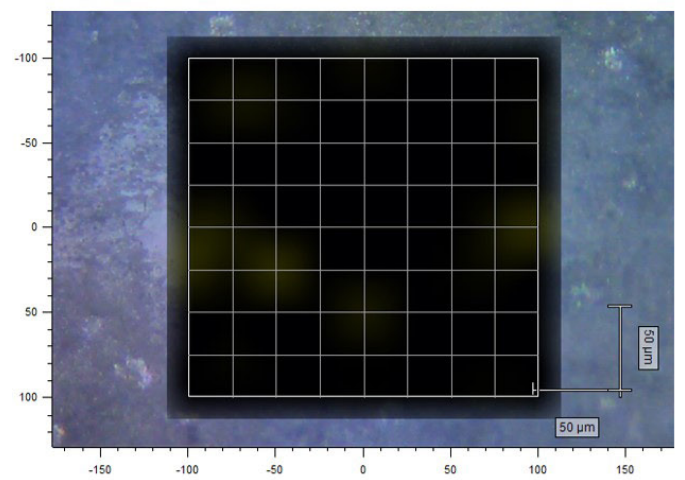

b) CBN0.375\%

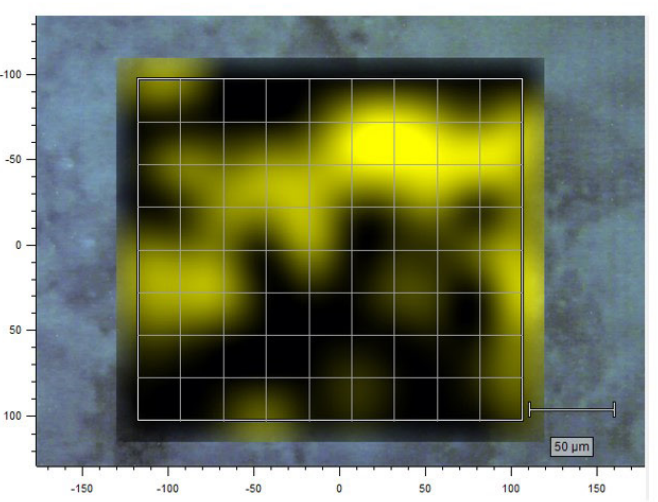

d) $\mathrm{CBN} 1.5 \%$

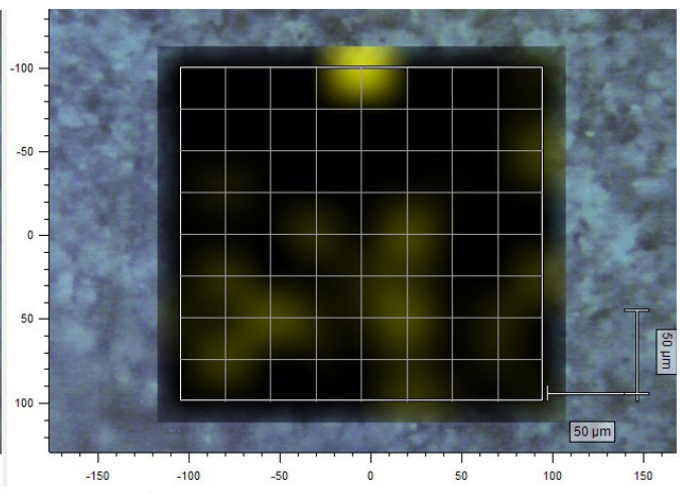

f) $\mathrm{CBN} 4 \%$

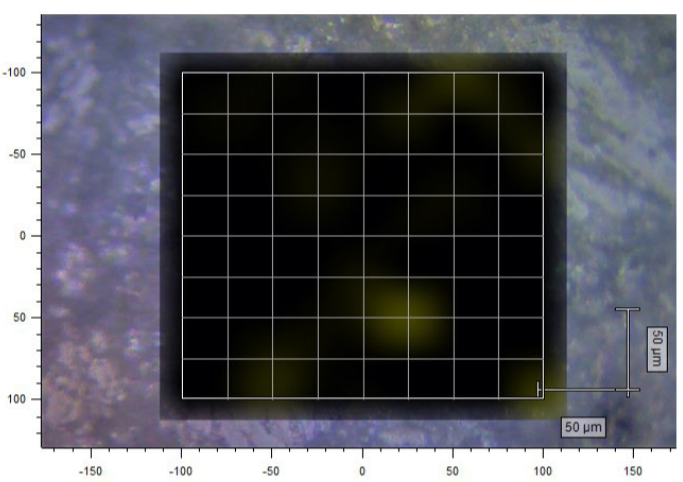

h) $\mathrm{CBN} 6 \%$

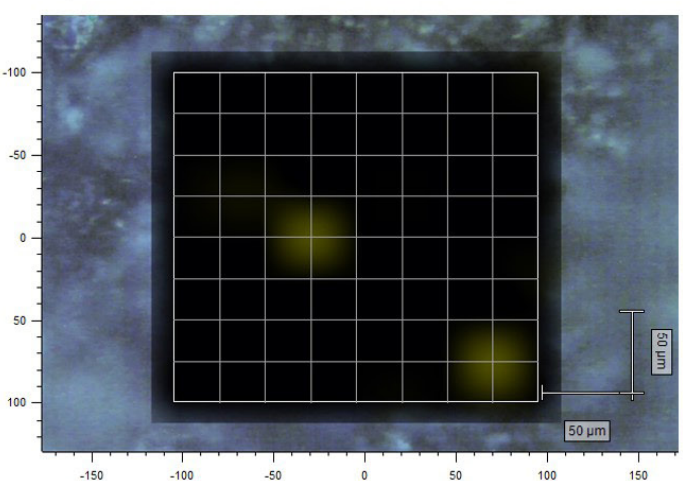

Figure 5. Raman maps for portlandite peaks at $356.63 \mathrm{~cm}^{-1}$ (brighter spots indicate higher peak intensities) of a cementitious matrix with different $\mathrm{CBN}$ contents at 28 days. 


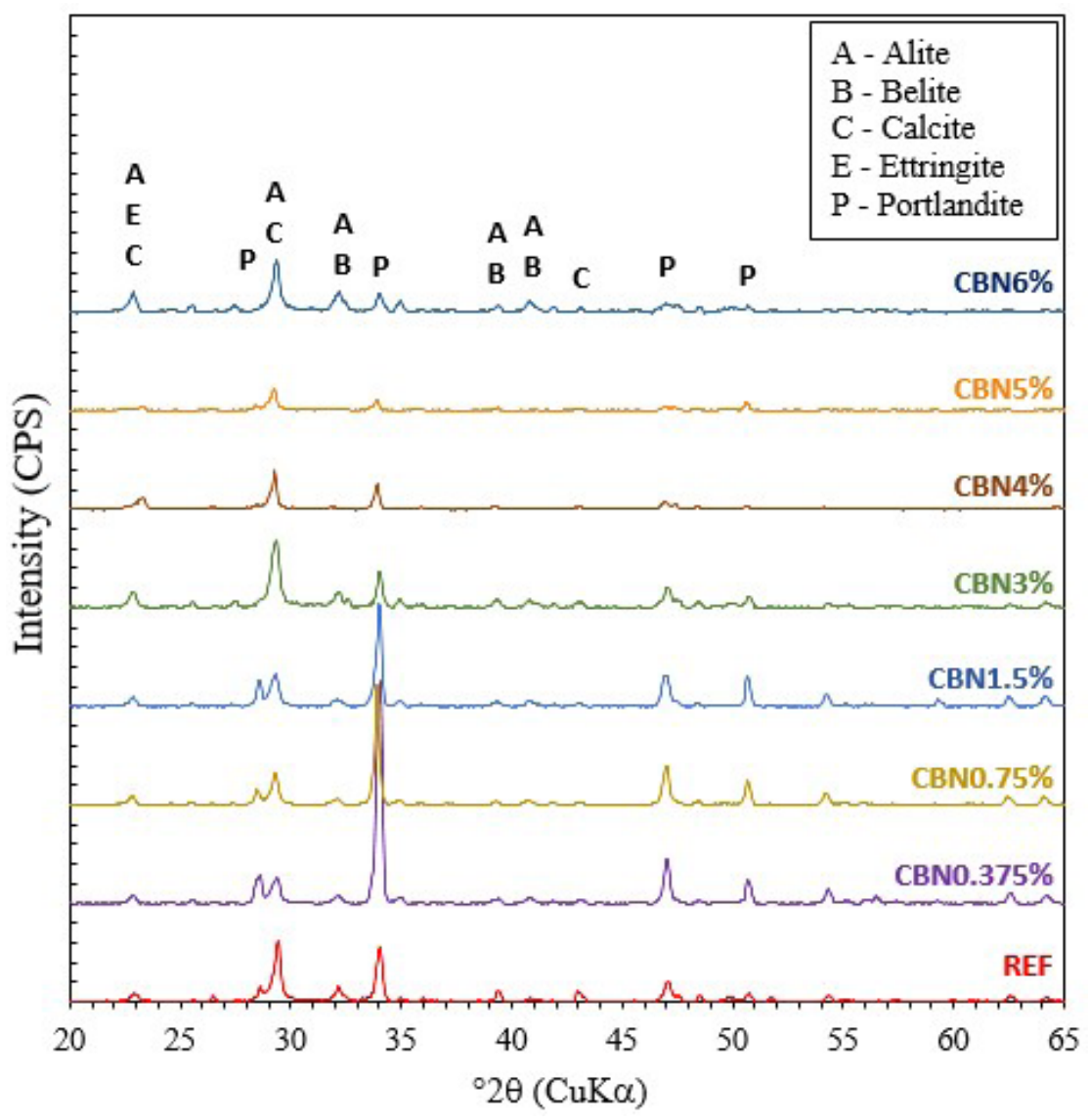

Figure 6. XRD spectra of a cementitious matrix with different CBN contents at 28 days.

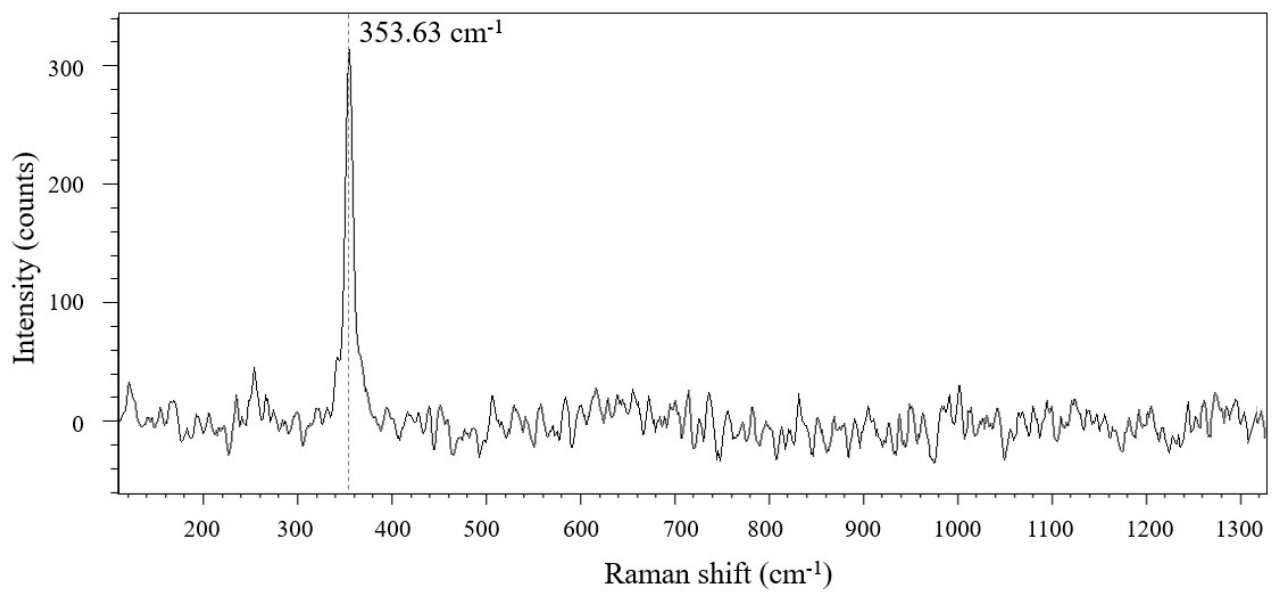

Figure 7. Typical Raman spectrum collected at locations with high portlandite concentration.

presented reversible changes in their electrical resistivity due to compressive deformations and stresses.

The piezoresistive behavior of the mortars and the relationship between FCR and strain are shown in Figure 10 and Figure 11 . Series with CBN content lower than $3 \%$ did not present piezoresistivity. The series with $\mathrm{CBN}$ content of $4 \%$ presented a strong piezoresistive effect, but a nonlinear relationship between strain and FCR was obtained.
The best piezoresistive responses were obtained in series with $5 \%$ and $6 \%$ of CBN. For each composite of these series, linear regression analyses with zero intercept were developed in order to propose an equation that provides the best fit to FCR vs. strain curves. The gauge factor of each specimen was taken as the angular coefficient of these regression equations. Gauge factors of 500, 487 and 561 were obtained for the three specimens with CBN content of $6 \%$, 
a) REF

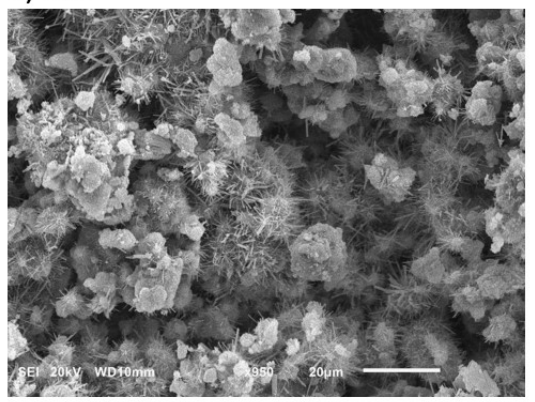

c) $\mathrm{CBN} 0.75 \%$

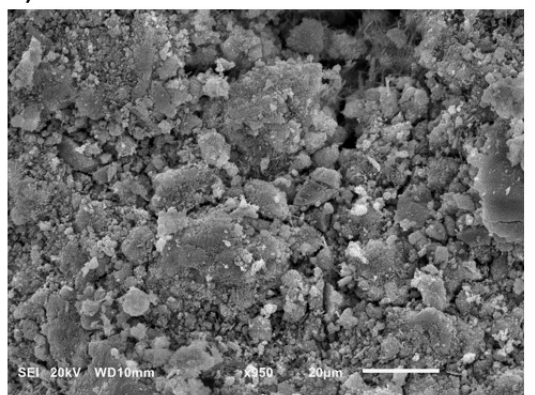

e) CBN3\%

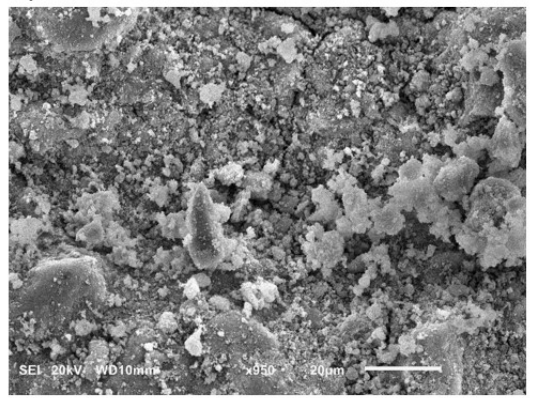

g) $\mathrm{CBN} 5 \%$

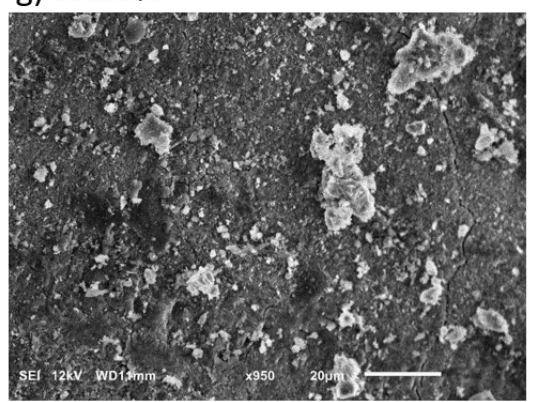

b) $\mathrm{CBN} 0.375 \%$

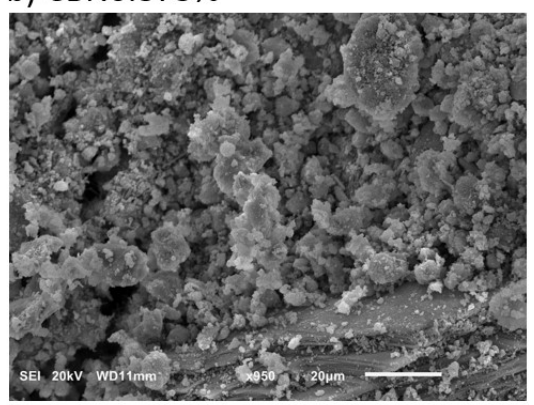

d) $\mathrm{CBN} 1.5 \%$

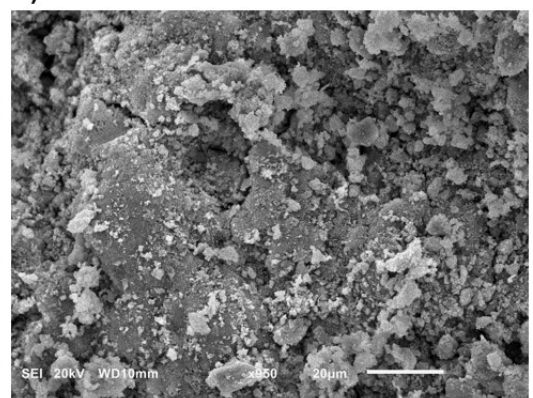

\section{f) $\mathrm{CBN} 4 \%$}

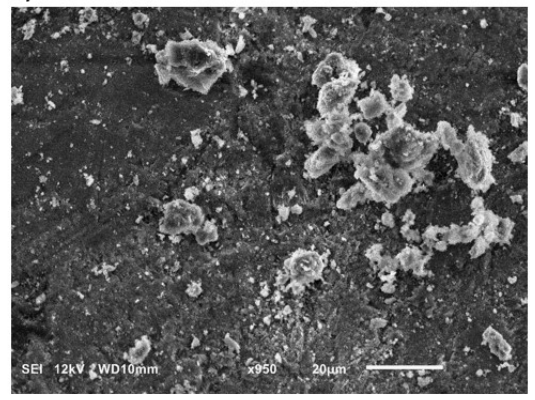

h) $\mathrm{CBN6} \%$

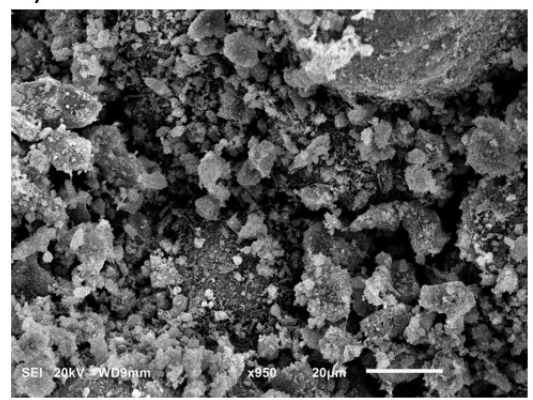

Figure 8. SEM images of a cementitious matrix with various CBN contents at 28 days.

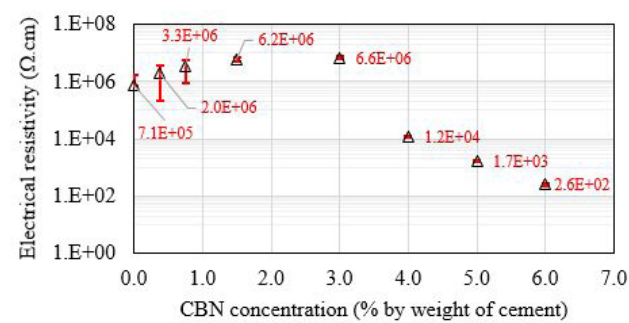

Figure 9. Electrical resistivity of mortars with different CBN contents at 28 days. while gauge factors of 129,82 and 121 were observed in the three specimens with CBN content of $5 \%$. The coefficient of determination $R^{2}$ of each model is approximately 0.99 , which demonstrates the excellent linearity and repeatability of these cement-based composites. It also suggests that they can be used as smart cement-based sensors for deformation monitoring in concrete structural elements.

Lower gauge factors have been reported in previous works that used only $\mathrm{CBN}$ as conductive nanofillers of cementitious composites. For instance, Li et al. ${ }^{15,17}$ observed 

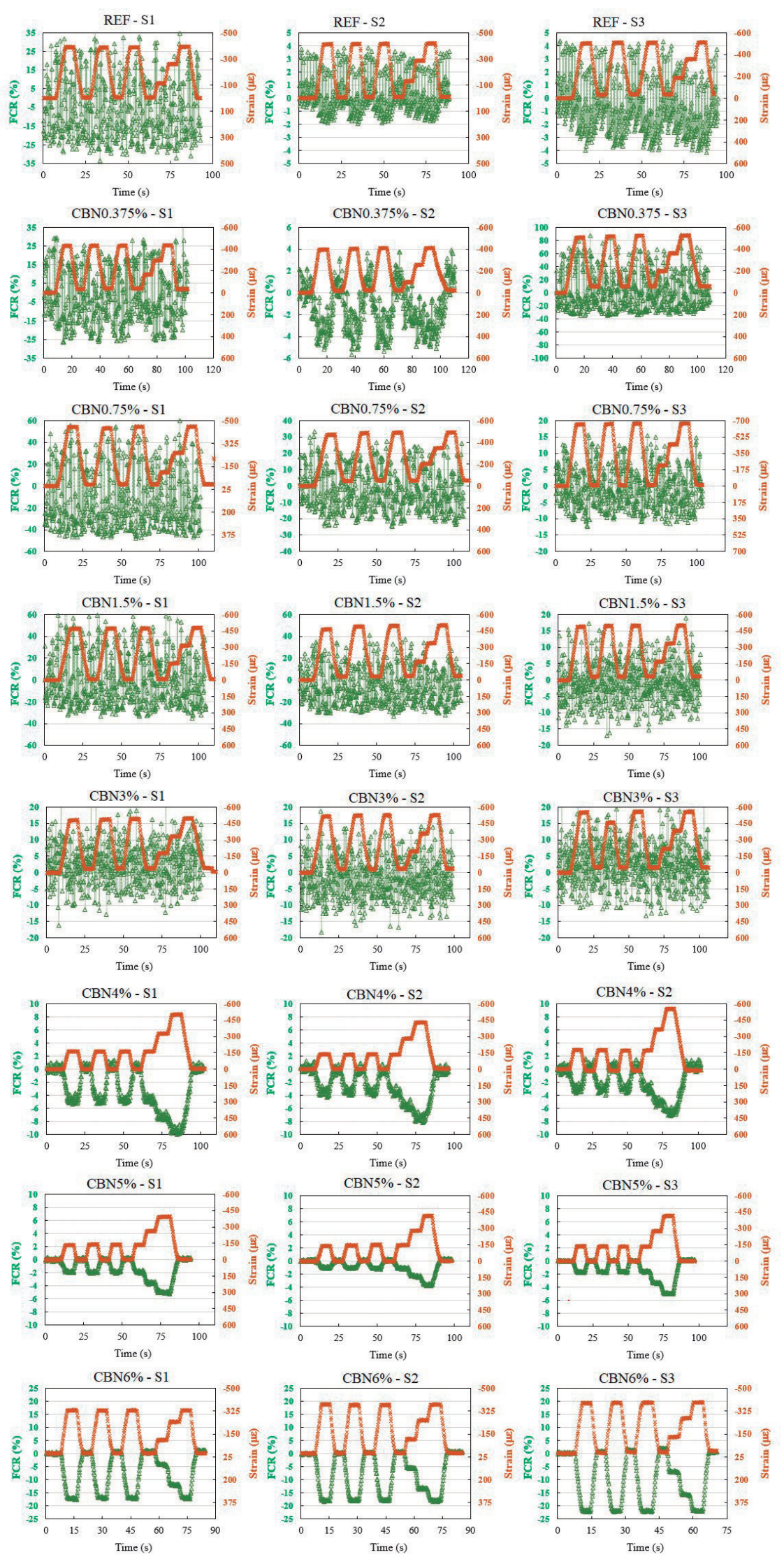

Figure 10. Piezoresistive response of the composites at 28 days. 

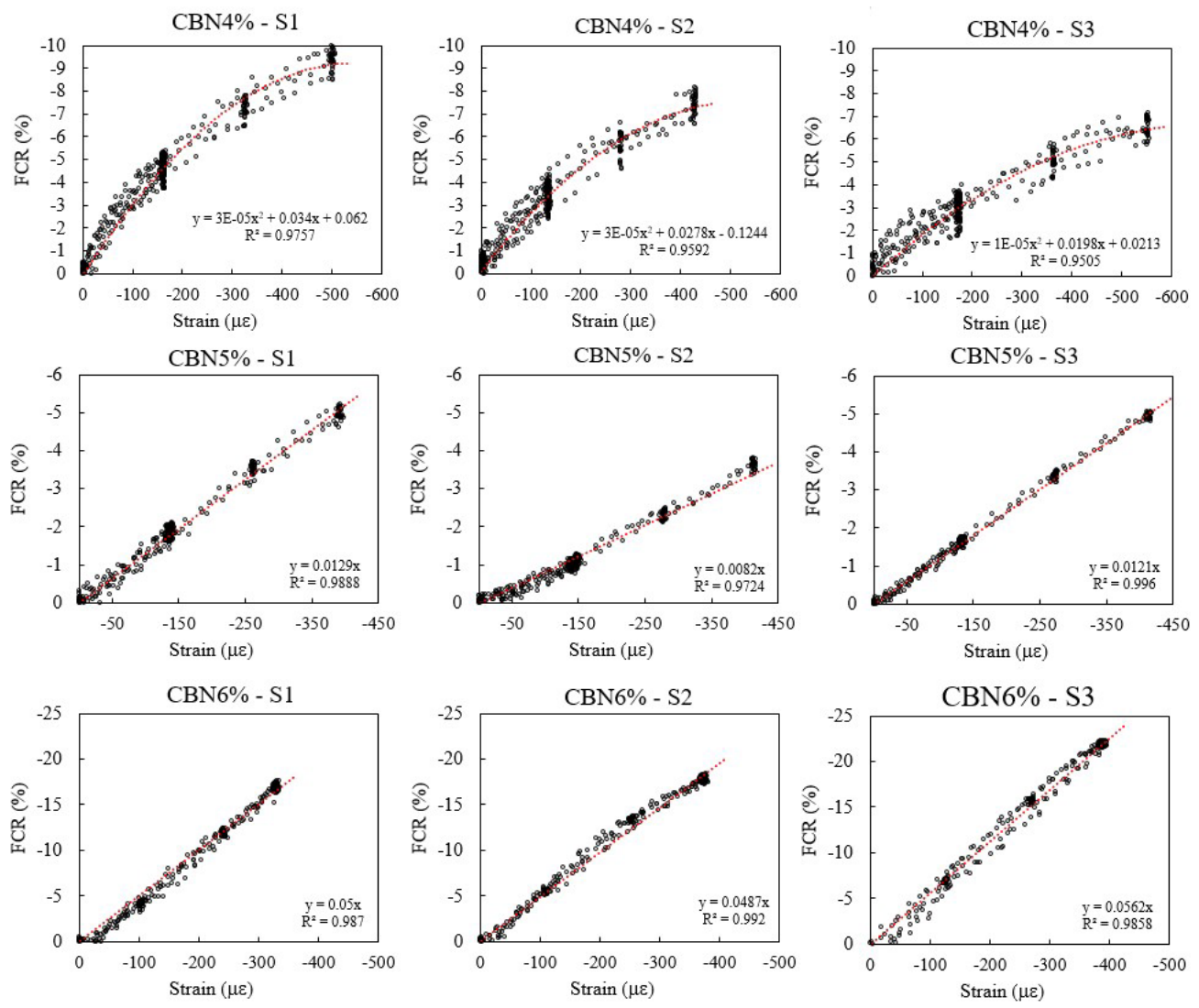

Figure 11. Relationship between FCR and strain of self-sensing composites.

good piezoresistive behavior in mortars containing $15 \%$ of CBN with average size of $120 \mathrm{~nm}$ : they presented gauge factors between 52.7 and 59.6. Monteiro et al. ${ }^{7}$ obtained gauge factors between 30.28 and 24.13 for mortars containing concentrations between $7 \%$ and $10 \%$ of CBN with average particle size of $120 \mathrm{~nm}$. However, all of these authors did not used sonication for improvement of dispersion of the conductive nanofillers. In the present work, ultrasonication was used and CBN were significantly smaller (average size of $20 \mathrm{~nm}$ ). Consequently, composites containing a much lower CBN concentration (5\% or $6 \%$ ) presented a strain sensibility much higher (gauge factors between 82 and 561).

Monteiro et al. ${ }^{5}$ also used an ultrasonication process for dispersion of nanofillers and obtained gauge factors between 40 and 60 in mortars containing $6.5 \%$ of CBN. However, they used CBN with average size between 30 and $40 \mathrm{~nm}$ (their DBP absorption number was not mentioned by the authors) and their composites had high sand/cement ratios $(2.32$, in mass). In this research, the use of CBN with small average size $(20 \mathrm{~nm})$ and small structure (DBP absorption number of $117 \mathrm{~cm}^{3} / 100 \mathrm{~g}$ ), combined to a lower sand/cement ratio (0.9, in mass) provided strain sensibility much higher than that reported in previous studies, which is an important contribution of this study to the area of innovative SHM technologies. There are many different types of CBN available in the market, with different average particle size, specific area and structure ${ }^{7}$. Another study has been recently developed by the authors of this paper to better elucidate the influence of CBN morphology and structure (DBP absorption number) on the mechanical and electrical properties of cementitious materials.

The optimum balance between mechanical properties and piezoresistive response was obtained for the CBN concentration of $5 \%$ (by weight of cement). Specimens with this nanofiller content presented high mechanical properties (average compressive strength of $25.4 \mathrm{MPa}$ and average modulus of elasticity of $14.2 \mathrm{GPa}$ ) and excellent self-sensing ability (average gauge factor of 111).

\section{Conclusion}

The present study brings the following conclusions:

1. Compressive strength, static modulus of elasticity and electrical resistivity of mortars increased for CBN contents between $0 \%$ and $3 \%$, and decreased when the $\mathrm{CBN}$ content ranges from $3 \%$ to $6 \%$.

2. A good relationship between compressive strength and static modulus of elasticity of mortars with CBN was established in this work, considering the square root functional model commonly used by structural design codes to correlate these mechanical properties.

3. The best improvements of compressive strength and static modulus of elasticity were provided by CBN contents between $2 \%$ and $3 \%$, while nanofiller concentrations of $5 \%$ and $6 \%$ provided the best 
improvements of sensing properties. A concentration of $5 \%$ of $\mathrm{CBN}$ provided low electrical resistivity and excellent piezoresistive response, without very significant strength and stiffness loss.

4. SEM images show that lower contents of $\mathrm{CBN}$ refined the cementitious matrix pores at the nanoscale and higher contents of $\mathrm{CBN}$ increased the volume of voids. Then, smaller $\mathrm{CBN}$ concentrations provided a densification of the cementitious matrix.

5. Raman spectroscopy and XRD analysis have been effectively used to investigate cement hydration mechanisms in mortars containing CBN. XRD diffratograms suggested significant amounts of alite and belite in specimens with higher nanofiller concentration. Raman maps and XRD spectra also indicated higher formation of portlandite in specimens with $\mathrm{CBN}$ contents between $0.375 \%$ and $3 \%$, which is related to improvements of the hydration process.

6. The optimum balance between mechanical and piezoresistive properties was obtained for the $\mathrm{CBN}$ concentration of $5 \%$ (by weight of cement).

\section{Acknowledgments}

This study was financed in part by the Coordenação de Aperfeiçoamento de Pessoal de Nível Superior - Brasil (CAPES) - Finance Code 001. The authors thank the support of Civil Engineering Department and Physics Department of the Universidade Federal de Viçosa. The authors acknowledge Birla Carbon, RESIDROX Chemical Solutions and MC Bauchemie for the materials supplied.

\section{References}

1. Wang L, Aslani F. A review on material design, performance, and practical application of electrically conductive cementitious composites. Constr Build Mater. 2019;229:116892. http://dx.doi. org/10.1016/j.conbuildmat.2019.116892.

2. Dong W, Li W, Tao Z, Wang K. Piezoresistive properties of cement-based sensors: review and perspective. Constr Build Mater. 2019;203:146-63. http://dx.doi.org/10.1016/j. conbuildmat.2019.01.081.

3. Ding S, Dong S, Ashour A, Han B. Development of sensing concrete: principles, properties and its applications. J Appl Phys. 2019;126(24):241101. http://dx.doi.org/10.1063/1.5128242.

4. Ubertini F, D'Alessandro A. Concrete with self-sensing properties. In Pacheco-Torgal F, Melchers RE, Belie N, Shi X, Van Tittelboom K, Saez Perez A, editors. Eco-efficient repair and rehabilitation of concrete infrastructures. Duxford: Woodhead Publishing; 2018. p. 501-30. http://dx.doi.org/10.1016/B9780-08-102181-1.00018-6.

5. Monteiro AO, Loredo A, Costa PMFJ, Oeser M, Cachim PB. A pressure-sensitive carbon black cement composite for traffic monitoring. Constr Build Mater. 2017;154:1079-86. http:// dx.doi.org/10.1016/j.conbuildmat.2017.08.053.

6. Huang Y, Li H, Qian S. Self-sensing properties of engineered cementitious composites. Constr Build Mater. 2018;174:25362. http://dx.doi.org/10.1016/j.conbuildmat.2018.04.129.

7. Monteiro AO, Cachim PB, Costa PMFJ. Costa PMFJ. Selfsensing piezoresistive cement composite loaded with carbon black particles. Cement Concr Compos. 2017;81:59-65. http:// dx.doi.org/10.1016/j.cemconcomp.2017.04.009.
8. Dai Y, Sun M, Liu C, Li Z. Electromagnetic wave absorbing characteristics of carbon black cement-based composites. Cement Concr Compos. 2010;32(7):508-13. http://dx.doi. org/10.1016/j.cemconcomp.2010.03.009.

9. Dong W, Li W, Lu N, Qu F, Vessalas K, Sheng D. Piezoresistive behaviours of cement-based sensor with carbon black subjected to various temperature and water content. Compos, Part B Eng. 2019;178:107488. http://dx.doi.org/10.1016/j. compositesb.2019.107488.

10. Rezania M, Panahandeh M, Razavi SMJ, Berto F. Experimental study of the simultaneous effect of nano-silica and nano-carbon black on permeability and mechanical properties of the concrete. Theor Appl Fract Mech. 2019;104:102391. http://dx.doi. org/10.1016/j.tafmec.2019.102391.

11. Dehghanpour H, Yilmaz K, Ipek M. Evaluation of recycled nano carbon black and waste erosion wires in electrically conductive concretes. Constr Build Mater. 2019;221:109-21. http://dx.doi. org/10.1016/j.conbuildmat.2019.06.025.

12. You I, Yoo D-Y, Kim S, Kim M-J, Zi G. Electrical and selfsensing properties of ultra-high-performance fiber-reinforced concrete with carbon nanotubes. Sensors. 2017;17(11):2481. http://dx.doi.org/10.3390/s17112481.

13. Han B, Ding S, Yu X. Intrinsic self-sensing concrete and structures: a review. Measurement. 2015;59:110-28. http:// dx.doi.org/10.1016/j.measurement.2014.09.048.

14. Han B, Yu X, Ou J. Self-sensing concrete in smart structures. Waltham, MA: Elsevier; 2015.

15. Li H, Xiao H, Ou J. Effect of compressive strain on electrical resistivity of carbon black-filled cement-based composites. Cement Concr Compos. 2006;28(9):824-8. http://dx.doi. org/10.1016/j.cemconcomp.2006.05.004.

16. Li H, Xiao H, Ou J. Electrical property of cement-based composites filled with carbon black under long-term wet and loading condition. Compos Sci Technol. 2008;68(9):2114-9. http://dx.doi.org/10.1016/j.compscitech.2008.03.007.

17. Li W, Dong W, Shen L, Castel A, Shah SP. Conductivity and piezoresistivity of nano-carbon black (NCB) enhanced functional cement-based sensors using polypropylene fibres. Mater Lett. 2020;270:127736. http://dx.doi.org/10.1016/j. matlet.2020.127736.

18. Dong W, Li W, Wang K, Guo Y, Sheng D, Shah SP. Piezoresistivity enhancement of functional carbon black filled cement-based sensor using polypropylene fibre. Powder Technol. 2020;373:18494. http://dx.doi.org/10.1016/j.powtec.2020.06.029.

19. Dong W, Li W, Luo Z, Long G, Vessalas K, Sheng D. Structural response monitoring of concrete beam under flexural loading using smart carbon black/cement-based sensors. Smart Mater Struct. 2020;29(6):065001. http://dx.doi.org/10.1088/1361$665 X / a b 7$ fef.

20. Zhang L, Ding S, Han B, Yu X, Ni Y-Q. Effect of water content on the piezoresistive property of smart cement-based materials with carbon nanotube/nanocarbon black composite filler. Compos, Part A Appl Sci Manuf. 2019;119:8-20. http:// dx.doi.org/10.1016/j.compositesa.2019.01.010.

21. Han B, Wang Y, Ding S, Yu X, Zhang L, Li Z, et al. Selfsensing cementitious composites incorporated with botryoid hybrid nano-carbon materials for smart infrastructures. J Intell Mater Syst Struct. 2017;28(6):699-727. http://dx.doi. org/10.1177/1045389X16657416.

22. Dong W, Li W, Shen L, Sheng D. Piezoresistive behaviours of carbon black cement-based sensors with layer-distributed conductive rubber fibres. Mater Des. 2019;182:108012. http:// dx.doi.org/10.1016/j.matdes.2019.108012.

23. ASTM: American Society for Testing and Materials. D655619a: standard test method for carbon black: total and external surface area by nitrogen adsorption. West Conshochen: ASTM; 2019. 
24. ASTM: American Society for Testing and Materials. D384914a: standard test method for carbon black -morphological characterization of carbon black using electron microscopy. West Conshochen: ASTM; 2014.

25. ASTM: American Society for Testing and Materials. ASTM C595/C595M-20: standard specification for blended hydraulic cements. West Conshochen: ASTM; 2020. 16 p.

26. Nalon GH, Ribeiro JCL, Araújo END, Pedroti LG, Carvalho JMF, Santos RF, et al. Residual mechanical properties of mortars containing carbon nanomaterials exposed to high temperatures. Constr Build Mater. 2021;275:122123. http:// dx.doi.org/10.1016/j.conbuildmat.2020.122123.

27. ABNT: Associação Brasileira de Normas Técnicas. ABNT NBR 13276: preparation of mortar for unit masonry and rendering with standard consistence index. Rio de Janeiro: ABNT; 2005.

28. Garg N, Wang K, Martin SW. A Raman spectroscopic study of the evolution of sulfates and hydroxides in cement-fly ash pastes. Cement Concr Res. 2013;53:91-103. http://dx.doi. org/10.1016/j.cemconres.2013.06.009.

29. Mohsen MO, Al-Nuaimi N, Abu Al-Rub RK, Senouci A, BaniHani KA. Effect of mixing duration on flexural strength of multi walled carbon nanotubes cementitious composites. Constr Build Mater. 2016;126:586-98. http://dx.doi.org/10.1016/j. conbuildmat.2016.09.073.

30. Kim HK, Park IS, Lee HK. Improved piezoresistive sensitivity and stability of CNT/cement mortar composites with low water-binder ratio. Compos Struct. 2014;116:713-9. http:// dx.doi.org/10.1016/j.compstruct.2014.06.007.

31. Yue Y, Wang JJ, Basheer PAM, Bai Y. In-situ monitoring of early hydration of clinker and Portland cement with optical fiber excitation Raman spectroscopy. Cement Concr Compos. 2020;112:103664. http://dx.doi.org/10.1016/j.cemconcomp.2020.103664.

32. Torréns-Martín D, Fernández-Carrasco L, Martínez-Ramírez S. Hydration of calcium aluminates and calcium sulfoaluminate studied by Raman spectroscopy. Cement Concr Res. 2013;47:4350. http://dx.doi.org/10.1016/j.cemconres.2013.01.015.

33. Machoviè V, Kopecky L, Němeček J, Kolar F, Svitilova ZB, Bittnar Z, et al. Raman micro-spectroscopy mapping and microstructural and micromechanical study of interfacial transition zone in concrete reinforced by poly(ethylene terephthalate) fibres. Ceram Silik. 2008;52:54-60.

34. Schmid T, Dariz P. Raman microspectroscopic imaging of binder remnants in historical mortars reveals processing conditions. Heritage. 2019;2(2):1662-83. http://dx.doi.org/10.3390/ heritage2020102.

35. Schmid T, Dariz P. Chemical imaging of historical mortars by Raman microscopy. Constr Build Mater. 2016;114:506-16. http://dx.doi.org/10.1016/j.conbuildmat.2016.03.153.

36. Liu F, Sun Z. Chemical mapping of cement pastes by using confocal Raman spectroscopy. Front Struct Civ Eng. 2016;10(2):168-73. http://dx.doi.org/10.1007/s11709-015-0323-9.

37. Takahashi $\mathrm{T}$. Chemical imaging of distribution of hydrates using Raman and photoluminescence spectroscopy. Tokyo: Nippon Steel \& Sumitomo Metal; 2018. (Technical Report; 118).

38. Black L, Breen C, Yarwood J, Deng C-S, Phipps J, Maitland $\mathrm{G}$. Hydration of tricalcium aluminate $(\mathrm{C} 3 \mathrm{~A})$ in the presence and absence of gypsum: studied by Raman spectroscopy and X-ray diffraction. J Mater Chem. 2006;16(13):1263. http:// dx.doi.org/10.1039/b509904h.

39. Black L, Breen C, Yarwood J, Garbev K, Stemmermann P, Gasharova B. Structural features of C-S-H(I) and its carbonation in air: a raman spectroscopic study. part II: carbonated phases. J Am Ceram Soc. 2007;90(3):908-17. http://dx.doi.org/10.1111/ j.1551-2916.2006.01429.x.

40. Frías M, Martínez-Ramírez S. Use of micro-Raman spectroscopy to study reaction kinetics in blended white cement pastes containing metakaolin. J Raman Spectrosc. 2009;40(12):2063-8. http://dx.doi.org/10.1002/jrs.2372.
41. Deng C-S, Breen C, Yarwood J, Habesch S, Phipps J, Craster $\mathrm{B}$, et al. Ageing of oilfield cement at high humidity: a combined FEG-ESEM and Raman microscopic investigation. J Mater Chem. 2002;12(10):3105-12. http://dx.doi.org/10.1039/b203127m.

42. Chollet M, Horgnies M. Analyses of the surfaces of concrete by Raman and FT-IR spectroscopies: comparative study of hardened samples after demoulding and after organic post-treatment. Surf Interface Anal. 2011;43(3):714-25. http://dx.doi.org/10.1002/ sia. 3548

43. Ubertini F, Laflamme S, D'Alessandro A. Smart cement paste with carbon nanotubes. In Loh KJ, Nagarajaiah S, editors. Innovative developments of advanced multifunctional nanocomposites in civil and structural engineering. Duxford: Elsevier; 2016, p. 97-120.

44. Downey A, D’Alessandro A, Ubertini F, Laflamme S, Geiger R. Biphasic DC measurement approach for enhanced measurement stability and multi-channel sampling of self-sensing multifunctional structural materials doped with carbon-based additives. Smart Mater Struct. 2017;26(6):065008. http://dx.doi. org/10.1088/1361-665X/aa6b66.

45. ABNT: Associação Brasileira de Normas Técnicas. ABNT NBR 8522: concrete: determination of the static elasticity and strain modulus. Rio de Janeiro: ABNT; 2017. 20 p.

46. Han B, Zhang L, Sun S, Yu X, Dong X, Wu T, et al. Electrostatic self-assembled carbon nanotube/nano carbon black composite fillers reinforced cement-based materials with multifunctionality. Compos, Part A Appl Sci Manuf. 2015;79:103-15. http://dx.doi. org/10.1016/j.compositesa.2015.09.016.

47. Han B, Zhang L, Ou J. Influence of water content on conductivity and piezoresistivity of cement-based material with both carbon fiber and carbon black. Journal of Wuhan University of Technology-Mater Sci Ed. 2010;25(1):147-51. http://dx.doi. org/10.1007/s11595-010-1147-z.

48. Han B, Yu X, Ou J. Effect of water content on the piezoresistivity of MWNT/cement composites. J Mater Sci. 2010;45(14):37149. http://dx.doi.org/10.1007/s10853-010-4414-7.

49. Mehta P, Monteiro P. Concrete: microstructure, properties and materials. São Paulo: IBRACON; 2014.

50. Black L, Purnell P, Hill J. Current themes in cement research. Adv Appl Ceramics. 2010;109(5):253-9. http://dx.doi.org/10. 1179/174367510X12714358363805.

51. Franus W., Panek R., Wdowin M. SEM investigation of microstructures in hydration products of Portland cement. In Polychroniadis E, Oral A, Ozer M, editors. 2nd International Multidisciplinary Microscopy and Microanalysis Congress. Cham: Springer; 2015. p. 105-12.

52. Taylor HF, Famy C, Scrivener K. Delayed ettringite formation. Cement Concr Res. 2001;31(5):683-93. http://dx.doi.org/10.1016/ S0008-8846(01)00466-5

53. Lothenbach B, Le Saout G, Gallucci E, Scrivener K. Influence of limestone on the hydration of Portland cements. Cement Concr Res. 2008;38(6):848-60. http://dx.doi.org/10.1016/j. cemconres.2008.01.002.

54. Lothenbach B, Zajac M. Application of thermodynamic modelling to hydrated cements. Cement Concr Res. 2019;123:105779. http://dx.doi.org/10.1016/j.cemconres.2019.105779.

55. Suh H, Jee H, Kim J, Kitagaki R, Ohki S, Woo S, et al. Influences of rehydration conditions on the mechanical and atomic structural recovery characteristics of Portland cement paste exposed to elevated temperatures. Constr Build Mater. 2020;235:117453. http://dx.doi.org/10.1016/j.conbuildmat.2019.117453.

56. Wei Y, Yao W, Xing X, Wu M. Quantitative evaluation of hydrated cement modified by silica fume using QXRD, 27Al MAS NMR, TG-DSC and selective dissolution techniques. Constr Build Mater. 2012;36:925-32. http://dx.doi.org/10.1016/j. conbuildmat.2012.06.075. 